\title{
Comparison Surgical Outcomes between Laparoscopic and Conventional Distal Gastrectomy for Early Gastric Cancer in Obese Patients
}

\author{
Young Sun Choi, M.D., Dong Jin Kim, M.D., Han Mo Yoo, M.D., Kyo Young Song, M.D., Cho Hyun Park, M.D. \\ Department of Surgery, College of Medicine, The Catholic University of Korea, Seoul, Korea
} Purpose: In this study, we explored the safety of laparoscopic gastrectomy in obese gastric cancer
patients compared with conventional open gastrectomy based on early surgical outcomes.

Methods: A total of 462 patients who underwent curative gastrectomy for early gastric adenocarcinoma from January 2000 to December 2014 were enrolled. Two obesity cohorts were defined according to a body mass index (BMI) of $\geq 25 \mathrm{~kg} / \mathrm{m}^{2}$ versus $\geq 30 \mathrm{~kg} / \mathrm{m}^{2}$. Those cohorts were further divided into the laparoscopic distal gastrectomy (LDG) and open distal gastrectomy (ODG) groups, and clinicopathologic characteristics were compared with early surgical results.

Results: There were no significant differences in clinicopathologic characteristics between the LDG and ODG groups in the BMI $\geq 25$ or BMI $\geq 30$ cohorts. For the overall complication rate, fewer complications were observed in the LDG than ODG group in both cohorts. Among the overall complications, significant differences were observed in the minor complication rates (Clavien-Dindo I or II), but no significant difference was observed in the rate of Clavien-Dindo III or higher complications. For risk factor analysis of postoperative complications, open distal gastrectomy, age $>60$ years, and BMI $\geq 30$ were independent risk factors for postoperative morbidity among all obese patients.

Conclusion: LDG may be a better procedure to improve surgical outcomes in patients with obesity undergoing surgery for early gastric cancer in terms of less excessive blood loss, shorter operation time, and lower complication rates.

Keywords: Stomach neoplasm, Laparoscopy, Complication, Obesity
Received June 27, 2017

Revised 1st August 1, 2017

2nd August 5, 2017

Accepted August 8, 2017

Corresponding author

Han Mo Yoo

Department of Surgery, Daejeon

St. Mary's Hospital, College of

Medicine, The Catholic University of

Korea, 64, Daeheung-ro, Jung-gu,

Daejeon 34943, Korea

Tel: +82-42-220-9520

Fax: +82-2-6442-4975

E-mail: kalpolipse@catholic.ac.kr

This is an Open Access article distributed under the terms of the Creative Commons Attribution Non-Commercial License (http:// creativecommons.org/licenses/by-nc/4.0/) which permits unrestricted non-commercial use, distribution, and reproduction in any medium, provided the original work is properly cited.

Copyright (C 2017 The Journal of Minimally Invasive Surgery. All rights reserved.

\section{INTRODUCTION}

Obesity is rapidly increasing on a global scale and is defined as excess fat accumulation, which can lead to health problems. The criteria for obesity is a body mass index (BMI) $\geq 30 \mathrm{~kg} /$ $\mathrm{m}^{2}$ in Western countries and $\geq 25 \mathrm{~kg} / \mathrm{m}^{2}$ in Asian countries. ${ }^{1}$ Globally, $39 \%$ and $13 \%$ of adults aged $\geq 18$ years were overweight and obese, respectively, in 2014. According to the Ko- rea National Health and Nutrition Examination Survey, the obesity rate in south Korea is increasing, from 25.8\% in 1998 to $32.8 \%$ in $2012 .^{2}$ As obesity in the population increases, the proportion of obese patients with gastric cancer is also increasing.

Generally, gastric cancer surgeries in obese patients are technically demanding, showing limited oncologic safety. Large amounts of intra-abdominal fat can obscure vascular 
Table 1. Clinicopathologic characteristics of the patients

\begin{tabular}{|c|c|c|c|c|c|c|}
\hline \multirow{2}{*}{ Variables } & \multicolumn{3}{|c|}{$\mathrm{BMI} \geq 25\left(\mathrm{~kg} / \mathrm{m}^{2}\right)(\mathrm{n}=426)$} & \multicolumn{3}{|c|}{$\mathrm{BMI} \geq 30\left(\mathrm{~kg} / \mathrm{m}^{2}\right)(\mathrm{n}=41)$} \\
\hline & LDG $(\%)(n=260)$ & ODG $(\%)(n=166)$ & $p$ value $^{\dagger}$ & LDG (\%) $(\mathrm{n}=24)$ & ODG (\%) (n=17) & $p$ value ${ }^{\dagger}$ \\
\hline Age (year) & $58.9 \pm 11.2^{*}$ & $59.8 \pm 9.9^{*}$ & 0.422 & $57.8 \pm 10.1^{*}$ & $61.2 \pm 9.9^{*}$ & 0.299 \\
\hline $\begin{array}{l}\text { Sex } \\
\text { Male } \\
\text { Female }\end{array}$ & $\begin{array}{r}182 \text { (70.0) } \\
78 \text { (30.0) }\end{array}$ & $\begin{array}{r}120 \text { (72.3) } \\
46(27.7)\end{array}$ & 0.662 & $\begin{array}{r}16(66.7) \\
8(33.3)\end{array}$ & $\begin{array}{r}11(64.7) \\
6(35.3)\end{array}$ & 1.000 \\
\hline BMI $\left(\mathrm{kg} / \mathrm{m}^{2}\right)$ & $27.3 \pm 2.2^{*}$ & $27.3 \pm 1.9^{*}$ & 0.918 & $32.7 \pm 2.6^{*}$ & $31.5 \pm 1.6^{*}$ & 0.093 \\
\hline $\begin{array}{l}\text { ECOG PS } \\
0 \\
1 \\
2 \\
3\end{array}$ & $\begin{array}{c}184(70.8) \\
68(26.2) \\
7(2.7) \\
1(0.4)\end{array}$ & $\begin{array}{c}120(72.3) \\
39(23.5) \\
7(4.2) \\
0(0)\end{array}$ & 0.736 & $\begin{array}{l}19(79.2) \\
5(20.8) \\
0(0) \\
0(0)\end{array}$ & $\begin{array}{l}9(52.9) \\
7(41.2) \\
1(5.9) \\
0(0)\end{array}$ & 0.115 \\
\hline $\begin{array}{l}\text { Number of comorbidities } \\
0 \\
1 \\
2 \\
\geq 3\end{array}$ & $\begin{array}{c}107(41.2) \\
111(42.7) \\
30(11.5) \\
12(4.6)\end{array}$ & $\begin{array}{l}64(38.6) \\
76(45.8) \\
14(8.4) \\
12(7.2)\end{array}$ & 0.470 & $\begin{array}{c}10(41.7) \\
10(41.7) \\
1(4.2) \\
3(12.5)\end{array}$ & $\begin{array}{l}4(23.5) \\
9(52.9) \\
1(5.9) \\
3(17.6)\end{array}$ & 0.780 \\
\hline $\begin{array}{l}\text { Smoking history } \\
\text { Non-smoker } \\
\text { Ex-smoker } \\
\text { Current smoker }\end{array}$ & $\begin{array}{r}150(57.7) \\
60(23.1) \\
50(19.2)\end{array}$ & $\begin{array}{l}94(56.6) \\
35(21.1) \\
37(22.3)\end{array}$ & 0.713 & $\begin{array}{r}13(54.2) \\
6(25.0) \\
5(20.8)\end{array}$ & $\begin{array}{l}8(47.1) \\
8(47.1) \\
1(5.9)\end{array}$ & 0.233 \\
\hline $\begin{array}{l}\text { Alcohol history } \\
\text { Non-drinker } \\
\text { Social drinker } \\
\text { Heavy drinker }\end{array}$ & $\begin{array}{c}145(55.8) \\
92(35.4) \\
23(8.8)\end{array}$ & $\begin{array}{l}91(54.8) \\
55(33.1) \\
20(12.0)\end{array}$ & 0.545 & $\begin{array}{r}13(54.2) \\
8(33.3) \\
3(12.5)\end{array}$ & $\begin{array}{l}7(41.2) \\
10(58.8) \\
0(0)\end{array}$ & 0.176 \\
\hline $\begin{array}{l}\text { Previous abdominal operation history } \\
\text { Absent } \\
\text { Present }\end{array}$ & $\begin{array}{r}210 \text { (80.8) } \\
50 \text { (19.2) }\end{array}$ & $\begin{array}{r}132 \text { (79.5) } \\
34 \text { (20.5) }\end{array}$ & 0.803 & $\begin{array}{r}15(62.5) \\
9(37.5)\end{array}$ & $\begin{array}{r}13(76.5) \\
4(23.5)\end{array}$ & 0.499 \\
\hline $\begin{array}{l}\text { Tumor location } \\
\text { Upper } \\
\text { Middle } \\
\text { Lower }\end{array}$ & $\begin{array}{c}5(2.0) \\
30(11.5) \\
225(86.5)\end{array}$ & $\begin{array}{c}6(3.6) \\
29(17.5) \\
131(78.9)\end{array}$ & 0.116 & $\begin{array}{c}0(0) \\
3(12.5) \\
21(87.5)\end{array}$ & $\begin{array}{r}2(11.8) \\
2(11.8) \\
13(76.5)\end{array}$ & 0.285 \\
\hline Tumor size (mm) & $2.6 \pm 1.5^{*}$ & $3.9 \pm 2.4^{*}$ & $<0.001$ & $2.6 \pm 1.7^{*}$ & $4.8 \pm 3.2^{*}$ & 0.005 \\
\hline $\begin{array}{l}\text { Differentiation } \\
\text { Differentiated } \\
\text { Undifferentiated }\end{array}$ & $\begin{array}{l}153 \text { (58.8) } \\
107 \text { (41.2) }\end{array}$ & $\begin{array}{l}82 \text { (49.4) } \\
84(50.6)\end{array}$ & 0.058 & $\begin{array}{l}14(58.3) \\
10(41.7)\end{array}$ & $\begin{array}{l}6(52.9) \\
8(47.1)\end{array}$ & 0.760 \\
\hline $\begin{array}{l}\text { N stage } \\
\text { NO } \\
\text { N1 } \\
\text { N2 } \\
\text { N3 }\end{array}$ & $\begin{array}{c}229(88.1) \\
20(7.7) \\
6(2.3) \\
5(1.9)\end{array}$ & $\begin{array}{c}142(85.5) \\
13(7.8) \\
8(4.8) \\
3(1.8)\end{array}$ & 0.648 & $\begin{array}{c}21(87.4) \\
1(4.2) \\
1(4.2) \\
1(4.2)\end{array}$ & $\begin{array}{l}12(70.6) \\
4(23.5) \\
1(5.8) \\
0(0)\end{array}$ & 0.247 \\
\hline
\end{tabular}

$\mathrm{BMI}=$ Body Mass Index; ECOG $=$ Eastern Cooperative Oncology Group. ${ }^{*}$ Standard deviation. ${ }^{\dagger}$ Indicates $\chi^{2}$ test. 
structures and normal surgical planes during surgery. Preoperative BMI is a risk factor for postoperative complications. ${ }^{3}$ Moreover, complete lymph node dissection is challenging during surgery in obese patients. These issues are equally challenging during laparoscopic surgery. In the past, laparoscopic surgery was not attempted in obese patients due to the above-mentioned problems. However, technical advancements have overcome these limitations. At this time, laparoscopic gastrectomy has advantages over open gastrectomy regarding postoperative outcomes and quality of life. ${ }^{4-6}$ In the recently published KLASS-01 trial morbidity and mortality report, laparoscopic gastrectomy showed advantages in terms of estimated blood loss, length of hospital stay, and overall complication rate, especially for wound complication. However, laparoscopic gastrectomy requires a longer operation time than that of open gastrectomy. Recently, the discrepancy in operation time has decreased due to technical improvements. ${ }^{8}$ However, the advantages of laparoscopic gastrectomy in obese patients remain controversial. In this study, we explored the safety of laparoscopic gastrectomy in terms of early surgical outcomes in obese gastric cancer patients.

\section{MATERIALS AND METHODS}

From January 2000 to December 2014, 4,272 patients with gastric adenocarcinoma underwent gastrectomy at the Depart- ment of Surgery, Seoul, St. Mary's Hospital. Eligible criteria were curative resection, distal gastrectomy, pathologically confirmed early gastric cancer, and range of lymph node dissection D1+ or greater. Patients who underwent palliative or non-curative resection or combined resection were excluded. The data were collected retrospectively from a prospectively collected database. Obesity and morbid obesity were defined as BMI $\geq 25$ and BMI $\geq 30$, respectively, according to AsianPacific guidelines. Among the 4,274 patients, two cohorts were defined: patients with $\mathrm{BMI} \geq 25$ and those with $\mathrm{BMI} \geq 30$. A total of 462 patients were included in the former cohort and 41 patients in the latter cohort. Those cohorts were further divided into the laparoscopic distal gastrectomy (LDG) and open distal gastrectomy (ODG) groups. Clinicopathologic characteristics and surgical results included the range of lymph node dissection, early surgical results including postoperative complications, and length of hospital stay. Comparisons of continuous variables were performed using Student's t-test and categorical variables were assessed using Pearson's $\chi^{2}$ test or a linear-by-linear association $\chi^{2}$ test. Postoperative complications were graded based on the Clavien-Dindo classification. ${ }^{9}$ In addition, univariate and multivariate analyses were performed to identify risk factors for the development of postoperative complications. This study followed the 7th UICC TNM staging system (according to the American Joint Committee on Cancer [AJCC] 7th edition). ${ }^{10}$

Table 2. Postoperative and surgical outcomes

\begin{tabular}{|c|c|c|c|c|c|c|}
\hline \multirow{2}{*}{ Variables } & \multicolumn{3}{|c|}{$\mathrm{BMI} \geq 25\left(\mathrm{~kg} / \mathrm{m}^{2}\right)(\mathrm{n}=426)$} & \multicolumn{3}{|c|}{$\mathrm{BMI} \geq 30\left(\mathrm{~kg} / \mathrm{m}^{2}\right)(\mathrm{n}=41)$} \\
\hline & $\operatorname{LDG}(\%)(n=260)$ & ODG $(\%)(n=166)$ & $p$ value ${ }^{\dagger}$ & $\operatorname{LDG}(\%)(n=24)$ & ODG $(\%)(n=17)$ & $p$ value $^{\dagger}$ \\
\hline $\begin{array}{l}\text { Reconstruction type } \\
\text { B-I } \\
\text { B-II } \\
\text { R-Y }\end{array}$ & $\begin{array}{r}45(17.3) \\
166(63.8) \\
49(18.8)\end{array}$ & $\begin{array}{c}15(9.0) \\
147(88.6) \\
4(2.4)\end{array}$ & $<0.001$ & $\begin{array}{r}3(12.5) \\
13(54.2) \\
8(33.3)\end{array}$ & $\begin{array}{r}4(23.5) \\
12(70.6) \\
1(5.9)\end{array}$ & 0.110 \\
\hline $\begin{array}{l}\text { LND } \\
\mathrm{D} 1+\beta \\
\geq \mathrm{D} 2\end{array}$ & $\begin{array}{r}173(66.5) \\
87(33.5)\end{array}$ & $\begin{array}{r}55 \text { (33.1) } \\
111(66.9)\end{array}$ & $<0.001$ & $\begin{array}{r}17(70.8) \\
7(29.2)\end{array}$ & $\begin{array}{r}5(29.4) \\
12(70.6)\end{array}$ & 0.012 \\
\hline Retrieved LNs & $39.5 \pm 15.2^{*}$ & $39.8 \pm 15.2^{*}$ & 0.834 & $41.1 \pm 14.5^{*}$ & $39.7 \pm 15.2^{*}$ & 0.754 \\
\hline $\begin{array}{l}\text { Combine resection } \\
\text { Yes } \\
\text { No }\end{array}$ & $\begin{array}{c}4(1.5) \\
256(98.5)\end{array}$ & $\begin{array}{c}2(1.2) \\
164(98.8)\end{array}$ & 1.000 & $\begin{array}{c}23(95.8) \\
1(4.2)\end{array}$ & $\begin{array}{c}17(100) \\
0(0)\end{array}$ & 1.000 \\
\hline Operation time (min) & $190.7 \pm 49.7^{*}$ & $200.5 \pm 41.1^{*}$ & 0.033 & $190.0 \pm 64.4^{*}$ & $206.8 \pm 50.1^{*}$ & 0.375 \\
\hline EBL (ml) & $155.2 \pm 124.9^{*}$ & $192.4 \pm 162.1^{*}$ & 0.008 & $151.9 \pm 100.2^{*}$ & $187.9 \pm 119.3^{*}$ & 0.300 \\
\hline First flatus (day) & $3.2 \pm 1.7^{*}$ & $3.1 \pm 1.0^{*}$ & 0.549 & $3.1 \pm 0.6^{*}$ & $3.4 \pm 0.5^{*}$ & 0.212 \\
\hline Postoperative hospital stay (days) & $8.2 \pm 4.7^{*}$ & $8.0 \pm 2.8^{*}$ & 0.629 & $9.6 \pm 5.8^{*}$ & $7.9 \pm 1.4^{*}$ & 0.231 \\
\hline
\end{tabular}

$\mathrm{LND}=$ Lymph Node Dissection; EBL $=$ Excessive Blood Loss. ${ }^{*}$ Standard deviation. ${ }^{\dagger}$ Indicates $\chi^{2}$ test. 


\section{RESULTS}

\section{Clinicopathological characteristics}

In the BMI $\geq 25$ cohort, no significant differences in patient characteristics including age, sex, ECOG, number of comorbidities, social history, or previous operation history were observed between the LDG and ODG groups. Tumor location, degree of differentiation, and $\mathrm{N}$ stage also showed no significant differences between the two groups. In the BMI $\geq 30$ cohort, similar results were observed between the two groups (excluding mean tumor size). Tumor size in the LDG group was $2.6 \pm 1.5 \mathrm{~cm}$, which was smaller than that $(3.9 \pm 2.4 \mathrm{~cm})$ in the ODG group (Table 1).

\section{Postoperative and surgical results}

In terms of surgical outcomes, there were differences in the type of reconstruction and extent of lymph node dissection between the groups in the BMI $\geq 25$ cohort and in the extent of lymph node dissection in the BMI $\geq 30$ cohort. Billroth-II anastomosis was performed more commonly in the LDG than in the ODG group. In addition, more D2 lymph node dissections were performed in the ODG than in the LDG (Table 2).

In the LDG group, 87 patients (33.5\%) underwent $>$ D2 lymph node dissection, and 173 patients $(66.5 \%)$ underwent D1+ lymph node dissection. In the ODG group, 111 patients (66.9\%) underwent $>$ D2 lymph node dissection and 55 patients (33.1\%) D1+ lymph node dissection. Nevertheless, the number of retrieved lymph nodes showed no significant difference between the two groups (LDG vs. ODG: $39.5 \pm 15.2$ vs. $39.8 \pm 15.2$ ). An extended operation time was required in the ODG group compared with the LDG group in the BMI $\geq 25$ cohort. However, the difference was minimal, and there was no significant difference in the BMI $\geq 30$ cohort. Less blood loss was observed in the LDG group $(155.2 \pm 124.9 \mathrm{ml})$ than in the ODG group $(192.4 \pm 162.1 \mathrm{ml})$ in the BMI $\geq 25$ cohort. The postoperative clinical course showed no significant differences between the

Table 3. Postoperative morbidities within 30 postoperative days

\begin{tabular}{|c|c|c|c|c|c|c|}
\hline \multirow{2}{*}{ Variables } & \multicolumn{3}{|c|}{$\mathrm{BMI} \geq 25\left(\mathrm{~kg} / \mathrm{m}^{2}\right)(\mathrm{n}=426)$} & \multicolumn{3}{|c|}{$\mathrm{BMI} \geq 30\left(\mathrm{~kg} / \mathrm{m}^{2}\right)(\mathrm{n}=41)$} \\
\hline & $\operatorname{LDG}(\%)(n=260)$ & ODG $(\%)(n=166)$ & $p$ value $^{\dagger}$ & LDG $(\%)(n=24)$ & ODG $(\%)(n=17)$ & $p$ value $^{\dagger}$ \\
\hline Total number of postoperative morbidity & $49(18.8)$ & $60(36.1)$ & $<0.001$ & $5(20.8)$ & $11(64.7)$ & 0.009 \\
\hline Grade I, II & $39(15)$ & $50(30.1)$ & & $4(16.7)$ & $11(64.7)$ & \\
\hline Grade III, IV & $10(3.8)$ & $10(6.0)$ & & $1(4.2)$ & $0(0)$ & \\
\hline Grade I & $14(5.4)$ & $21(12.7)$ & 0.011 & $0(0)$ & $4(23.5)$ & 0.024 \\
\hline Grade II & $25(9.6)$ & $29(17.5)$ & 0.024 & $4(16.7)$ & $7(41.2)$ & 0.151 \\
\hline Grade Illa & $8(3.1)$ & $10(6.0)$ & 0.216 & $1(4.2)$ & $0(0)$ & 1.000 \\
\hline Grade IIIb & $1(0.4)$ & $0(0)$ & 1.000 & $0(0)$ & $0(0)$ & 1.000 \\
\hline Grade IVa & $1(0.4)$ & $0(0)$ & 1.000 & $0(0)$ & $0(0)$ & 1.000 \\
\hline \multicolumn{7}{|l|}{ Medical } \\
\hline Pulmonary & $7(2.7)$ & $17(10.2)$ & & $0(0)$ & $4(23.5)$ & \\
\hline Cardiovascular & $0(0)$ & $2(1.2)$ & & $0(0)$ & $0(0)$ & \\
\hline Hepatic & $1(0.4)$ & $2(1.2)$ & & $0(0)$ & $1(5.8)$ & \\
\hline Urinary & $3(1.2)$ & $1(0.6)$ & & $0(0)$ & $0(0)$ & \\
\hline \multicolumn{7}{|l|}{ Intra-abdominal } \\
\hline Abscess & $0(0)$ & $1(0.6)$ & & $0(0)$ & $0(0)$ & \\
\hline Anastomosis bleeding & $1(0.4)$ & $0(0)$ & & $0(0)$ & $0(0)$ & \\
\hline Anastomosis leakage & $5(1.9)$ & $3(1.8)$ & & $1(4.2)$ & $1(5.8)$ & \\
\hline Anastomosis stenosis & $3(1.2)$ & $1(0.6)$ & & $0(0)$ & $0(0)$ & \\
\hline Bleeding & $8(3.1)$ & $2(1.2)$ & & $0(0)$ & $0(0)$ & \\
\hline lleus & $14(5.4)$ & $10(6.0)$ & & $2(8.3)$ & $0(0)$ & \\
\hline Pancreatitis & $1(0.4)$ & $3(0.8)$ & & $1(4.2)$ & $0(0)$ & \\
\hline Wound complications & $3(1.2)$ & $18(10.8)$ & & $0(0)$ & $5(29.4)$ & \\
\hline Others & $3(1.2)$ & $0(0)$ & & $1(4.2)$ & $0(0)$ & \\
\hline
\end{tabular}

${ }^{\dagger}$ Indicates $\chi^{2}$ test. 
two groups in terms of flatus day or length of hospital stay.

\section{Postoperative complications}

There were more overall complications in the ODG than in the LDG group in both cohorts. Among the complications,

Table 4. Risk factors for postoperative morbidity

\begin{tabular}{|c|c|c|c|c|c|}
\hline \multirow{2}{*}{ Variables } & \multicolumn{3}{|c|}{ Univariate analysis } & \multicolumn{2}{|c|}{ Multivariate analysis } \\
\hline & Number of patients ( $n=426$ ) & Morbidities (\%) & $p$ value $^{\ddagger}$ & Odds ratio & $p$ value $^{\ddagger}$ \\
\hline Operative approach & & & $<0.001$ & & $<0.001$ \\
\hline Open & 166 & $60(36.1)$ & & 1 & \\
\hline Laparoscopy & 260 & $49(18.8)$ & & 0.431 (0.273 0.683) & \\
\hline Age (years) & & & 0.004 & & 0.004 \\
\hline$<60$ & 213 & $41(19.2)$ & & 1 & \\
\hline$\geq 60$ & 213 & $68(31.9)$ & & $1.987(1.252 \sim 3.153)$ & \\
\hline Sex & & & 0.038 & & 0.057 \\
\hline Male & 302 & $86(28.5)$ & & 1 & \\
\hline Female & 124 & $12(18.5)$ & & $0.592(0.344 \sim 1.020)$ & \\
\hline $\mathrm{BMI}$ & & & 0.041 & & 0.039 \\
\hline$<30$ & 385 & $93(24.2)$ & & 1 & \\
\hline$\geq 30$ & 41 & $16(39.0)$ & & $2.106(1.039 \sim 4.269)$ & \\
\hline ECOG PS & & & 0.547 & & \\
\hline 0,1 & 411 & $104(25.3)$ & & & \\
\hline 2,3 & 15 & 5 (33.3) & & & \\
\hline Comorbidities & & & 1.000 & & \\
\hline Absent & 420 & $170(25.5)$ & & & \\
\hline Present & 6 & 2 (33.3) & & & \\
\hline History of abdominal surgery & & & 0.488 & & \\
\hline Absent & 342 & $85(24.9)$ & & & \\
\hline Present & 84 & $24(28.6)$ & & & \\
\hline Reconstruction type & & & 0.100 & & \\
\hline B-I & 60 & $18(30.0)$ & & & \\
\hline B-II & 313 & $72(23.0)$ & & & \\
\hline R-Y & 53 & $19(35.8)$ & & & \\
\hline LND & & & 1.000 & & \\
\hline$D 1+\beta$ & 228 & $58(25.4)$ & & & \\
\hline $\mathrm{D} 2$ & 198 & $51(25.8)$ & & & \\
\hline Operation time (min) & & & 0.045 & & 0.158 \\
\hline$<200$ & 228 & $49(21.5)$ & & 1 & \\
\hline$\geq 200$ & 198 & $60(30.3)$ & & $1.396(0.879 \sim 2.216)$ & \\
\hline $\mathrm{EBL}(\mathrm{mll}$ & & & 0.094 & & \\
\hline$<150$ & 195 & $42(21.5)$ & & & \\
\hline$\geq 150$ & 231 & $67(29.0)$ & & & \\
\hline pN stage & & & 1.000 & & \\
\hline NO & 371 & $95(25.6)$ & & & \\
\hline $\mathrm{N} 1 \sim 3$ & 55 & $14(25.5)$ & & & \\
\hline
\end{tabular}

Significant values are indicated in bold. BMI = Body Mass Index; ECOG = Eastern Cooperative Oncology Group. ${ }^{\ddagger}$ Binary logistic regression. 
significant differences were observed in the rates of ClavienDindo I and II complications (Table 3), but not Clavien-Dindo III and IV complications, between the two groups in both co- $^{-}$ horts.

The most common complications observed in the LDG group were ileus and bleeding, pulmonary complications, and anastomosis leakage. Pulmonary and wound complications were more common in the ODG group than in the LDG group and represented the main differences in terms of complications between the two groups. Based on risk factor evaluation, open distal gastrectomy, age $>60$ years, and BMI $\geq 30$ were independent risk factors for postoperative morbidity among obese patients (Table 4).

\section{DISCUSSION}

Major advancements in laparoscopic surgery for gastric cancer have been achieved since Kitano et al. first introduced laparoscopy-assisted distal gastrectomy in 1994. ${ }^{11}$ Subsequently, several retrospective and prospective studies have explored the surgical and oncologic safety of this technique. A metaanalysis of seven randomized controlled trials concluded that laparoscopic assisted gastrectomy significantly reduced blood loss and postoperative complications compared with open distal gastrectomy. ${ }^{12}$

Obese patients undergoing surgery have been examined in several reports. The postoperative complication rate varies among studies. Some studies have suggested that obesity does not affect postoperative morbidity or mortality. ${ }^{13,14}$ However, a longer operation time has been noted in obese patients.

This study evaluated the postoperative complication rate after laparoscopic distal gastrectomy and the safety of laparoscopic distal gastrectomy in patients with a high BMI. The overall complication rate was higher in the ODG than in the LDG group in both cohorts. Specifically, the major complication rates did not differ between the two groups. However, minor complications, especially pulmonary and wound complications, were more common in the ODG group. Although more patients underwent lymph node dissection of $>\mathrm{D} 2$ in the ODG group compared with the LDG group, the number of retrieved lymph nodes did not differ between the two groups. In the BMI $\geq 25$ cohort, the ODG group required a longer operation time. However, in the BMI $\geq 30$ cohort, no significant difference in operation time was observed between the groups. Estimated blood loss was lower in the LDG group, but the postoperative clinical course showed no significant difference.

Kim $\mathrm{W}$ et al. reported that the wound complication rate of the LDG group was significantly lower than that in the ODG group. In our study, wound complications were more common in the ODG group. In obese patients, the risk of wound infec- tions is likely to increase due to abundant subcutaneous fat.

In this study, pulmonary complications were significantly less common in the laparoscopic surgery group. Although objective measurements of postoperative pain were not performed, less pain in the LDG group allowed for early ambulation and prevented pulmonary complications.

In general, surgery in obese patients is associated with technical difficulties and a high complication rate. Especially in surgeries for cancer, in which sufficient lymph node dissection is important for curative resection, a large amount of intraabdominal fat may obscure anatomical structures and hamper lymph node dissection. Laparoscopic gastrectomy for stomach cancer in patients with a high BMI is technically challenging; thus, the safety of this approach should be explored.

Based on our results, laparoscopic surgery can be more difficult during lymph node dissection for obese patients than for non-obese patients. However, laparoscopic surgery is not inferior to open surgery in obese patients.

This study has several limitations. First, it was designed as a single-institutional retrospective study with a focus on early gastric cancer. Further randomized controlled trials conducted in large cohorts are required to confirm the results of this study. Second, we enrolled patients from 2000 to 2014. In early 2000, the majority of surgeons preferred open gastrectomy over laparoscopic gastrectomy. Over time, as laparoscopic instruments became more developed and surgeons' experiences increased, the preference shifted to laparoscopy. Patients who underwent laparoscopic gastrectomy at an earlier date may have had higher complication rates. In addition, the surgeon's preference may lead to selection bias. Third, to ensure the safety of laparoscopic gastrectomy in obese patients, a comparison between obese patients and normal- or low-weight patients is required. In addition, future studies should explore the long-term safety, including cancer recurrence and diseasefree survival rates, of laparoscopic gastrectomy in obese patients with gastric cancer.

In conclusion, LDG may improve surgical outcomes in obese patients undergoing surgery for early gastric cancer in terms of less excessive blood loss, shorter operation times, and lower complication rates. The conventional open gastrectomy approach, older age, and higher BMI are associated with postoperative morbidity in obese patients with early gastric cancer.

\section{REFERENCES}

1) Ogden CL, Carroll MD, Curtin LR, McDowell MA, Tabak CJ, Flegal KM. Prevalence of overweight and obesity in the United States, 1999-2004. Jama 2006;295:1549-1555.

2) Ministry of Health and Welfare, Korea Centers for Disease Control and Prevention. Korea Health Statistics 2015: Korea National 
Health and Nutrition Examination Survey (KNHANES VI-3). Sejong: Ministry of Health and Welfare; 2016.

3) Kim MG, Yook JH, Kim KC, et al. Influence of obesity on early surgical outcomes of laparoscopic-assisted gastrectomy in gastric cancer. Surg Laparosc Endosc Percutan Tech 2011;21:151-154.

4) Hayashi H, Ochiai T, Shimada H, Gunji Y. Prospective randomized study of open versus laparoscopy-assisted distal gastrectomy with extraperigastric lymph node dissection for early gastric cancer. Surg Endosc 2005;19:1172-1176.

5) Kim YW, Baik YH, Yun YH, et al. Improved quality of life outcomes after laparoscopy-assisted distal gastrectomy for early gastric cancer: results of a prospective randomized clinical trial. Ann Surg 2008;248:721-727.

6) Lee JH, Han HS, Lee JH. A prospective randomized study comparing open vs laparoscopy-assisted distal gastrectomy in early gastric cancer: early results. Surg Endosc 2005;19:168-173.

7) Kim W, Kim HH, Han SU, et al. Decreased Morbidity of Laparoscopic Distal Gastrectomy Compared With Open Distal Gastrectomy for Stage I Gastric Cancer: Short-term Outcomes From a Multicenter Randomized Controlled Trial (KLASS-01). Ann Surg 2016;263:28-35.
8) Mochiki E, Kamiyama Y, Aihara R, Nakabayashi T, Asao T, Kuwano H. Laparoscopic assisted distal gastrectomy for early gastric cancer: Five years' experience. Surgery 2005;137:317-322.

9) Dindo D, Demartines N, Clavien PA. Classification of surgical complications: a new proposal with evaluation in a cohort of 6336 patients and results of a survey. Ann Surg 2004;240:205-213.

10) Washington K. 7th edition of the AJCC cancer staging manual: stomach. Ann Surg Oncol 2010;17:3077-3079.

11) Kitano S, Iso Y, Moriyama M, Sugimachi K. Laparoscopy-assisted Billroth I gastrectomy. Surg Laparosc Endosc 1994;4:146-148.

12) Deng Y, Zhang Y, Guo TK. Laparoscopy-assisted versus open distal gastrectomy for early gastric cancer: A meta-analysis based on seven randomized controlled trials. Surg Oncol 2015;24:71-77.

13) Yamada H, Kojima K, Inokuchi M, Kawano T, Sugihara K. Effect of obesity on technical feasibility and postoperative outcomes of laparoscopy-assisted distal gastrectomy--comparison with open distal gastrectomy. J Gastrointest Surg 2008;12:997-1004.

14) Yasuda $K$, Inomata M, Shiraishi N, Izumi K, Ishikawa K, Kitano S. Laparoscopy-assisted distal gastrectomy for early gastric cancer in obese and nonobese patients. Surg Endosc 2004;18:1253-1256. 